\title{
A taste for borders
}

\author{
Ossi Naukkarinen
}




\section{Introduction}

One of the most important questions confronting every academic discipline is how it identifies and sometimes even defines its objects of research and itself as a discipline. Scholars of history, politics, mathematics, medicine, chemistry as well as of every other field of knowledge face exactly the same problem. It is generally expected that those doing research in philosophical aesthetics should have a conception of what is 'the aesthetic' (so neatly referred to in German as das Ästhetische), 'aesthetic experience', 'aesthetic features' and 'aesthetic terms' - or whether such things exist at all - and also of what the discipline focusing on such problems, i.e., aesthetics, consists.

A typical way of outlining aesthetics, both as an object of research and as a way of doing research, is to postulate borderlines for it. In so doing, one makes use of a spatial metaphor according to which aesthetics is conceived of as an area or a field inside of which certain things exist, with everything else being excluded. By drawing borderlines one wishes to separate aesthetics from other 'fields' and the phenomena that belong to them.

Although this way of thinking is fairly common and it feels easy to adopt it, it has consequences that are apt to blur our understanding of certain features of aesthetic practices and the discipline of aesthetics.

My aim is to (1) analyze the metaphor of the boundary in aesthetics a bit more deeply, (2) point out some difficulties that arise when we use it and (3) suggest another, more useful metaphor.

\section{Borderline metaphors}

When one talks about concrete, often visually detectable borders the concept is very easy to understand. A borderline is something that separates, say, one building site from another. On one side of the border the land and the buildings are my property, outside of it they belong to someone else. Such a borderline can easily be made visible with a fence or a ditch. A fence might have been made because it signals that the boundary is not meant to be crossed without a permission. In that case, the border is intended to be tight: trespassers might be unwanted for they are thought to be harmful, whereas flies and butterflies are ignored because they cannot do any harm - they may cross the border. Here, the borderline - even if it is connected with a fairly abstract ethical and juridical system - is very concrete and easy to discern. 
1 The interpretation of metaphors presented by Lakoff and Johnson is only one possibility. A good overview on the field of metaphor research can be found in Enzenberg 1998.

2 There are other schemas as well, such as the source-path-goal schema; on them see Lakoff and Johnson 1999, chapter 3 .
Such concrete, tangible borderlines also function as the source for metaphorical uses of the concept. In many cases the border metaphor is used when no literal expression for the thing is question can be found or when one wants to make use of an unusual expression. One can say, for example, that "people should have some borders they do not cross in their behavior" or, to use a different expression with practically the same meaning in this context, "imagination has its limits". Dying, also, is sometimes referred to by the expression "crossing the ultimate border".

One should note that there is nothing unusual in using metaphors. On the contrary, they are in use all the time, and this text is full of them if one reads it carefully. George Lakoff and Mark Johnson (1980 and especially 1999) have showed this very clearly. One uses metaphors almost inevitably when talking about such abstract issues as time, change, knowledge, love, and the like. According to Lakoff and Johnson, metaphors are expressions that have their origins in physical, embodied, sensorimotor experiences of the world, in experiences we all have because we live in this particular world through our bodies. Such experiences are, so to speak, source-domains which structure our understanding in other domains, called target-domains; we also use conceptual tools acquired in physical interaction with the world in situations where we do not use them for discussing such interactions as such. With their help we make sense of many other things as well. Because we know what it is to move our body or to travel (source-domain), we can think about time (target-domain), too, as something that moves onwards, even if it is hard to say what that might mean, taken literally. In addition, when something changes, the process can be thought of as movement; if I change my mind it can be conceived of (metaphorically) as me moving from one opinion to another. Still further, if I know something, I can describe it as grasping it. ${ }^{1}$

The so-called basic or primary metaphors, i.e. metaphors that are very often used, can be seen to form groups, and one important group follows the so-called container schema. ${ }^{2}$ The expression 'container schema' refers to our habit of conceptualizing things with the help of metaphors based on our knowledge of things that can literally contain other things, like containers, boxes and envelopes do. For example, we can conceive of conceptual categories as enclosures, or e-mail messages as packages.

Something like the container schema is exactly what is often used when we conceive of aesthetics with the help of boundary metaphors, with or without the word 'borderline'. Then, we see aes- 
thetics as something that contains something and excludes something else. And the container has its borders or limits, so to speak. It is easy to find expressions which are connectable with border metaphors that can be classified in this schema: "Aesthetics is a field of knowledge that deals with..." "Problems of aesthetics include..." "In aesthetics..." The theme of the annual meeting of the Nordic Society of Aesthetics in May 2003 was The Borderlines of Aesthetics.

It is possible, and even probable, that one cannot conceive of aesthetics at all without using some metaphors, but the point is that one has to be very careful with choosing them because they all have consequences for our thinking. I believe, for example, that for some purposes there are better alternatives to thinking about the aesthetic in terms of borders.

\section{The problems of boundary metaphors for aesthetics}

On an abstract theoretical level, drawing borders for aesthetics seems possible. One can say, in a common way, that the field of aesthetics includes, say, questions about the philosophy of art and beauty, and that ethical or ecological questions do not belong there. Because environmental aesthetics is often interested in such 'other' questions, it has sometimes seen to be situated somewhere on the borders between aesthetics and some other field.

But one faces problems right away when one moves any closer to more concrete and detailed examples. Where, exactly, is the border between art or beauty and something else in Robert Musil's novel Der Mann ohne Eigenschaften? Where, if we discuss a painting by Gerhard Richter, are aesthetic issues situated? Which things belong to which side of the border in assessing a view in the Helsinki archipelago? Indeed, on which basis can we omit, say, an ethical or ecological question anywhere?

Let's attempt to clarify the issues by considering a strawberry red Toyota Corolla sedan from the year 1993.

First of all, even if the chosen example is a car, it could be anything else. This reminds us of the fact that it is possible to talk about the aesthetics of anything whatsoever: of cars, human beings, flowers, musical compositions, paintings, landscapes, alligators, wars, houses, and marriages. This, I believe, has been widely accepted for a long time now. The simple but important consequence of this notion is that the borderlines of aesthetics many wish to find are unable to separate some particular types of objects from any others. Thus, the metaphor is useless in this sense because that sort of borders simply do not exist. 
Secondly, when we talk about a concrete, individual case, say, about a particular car, the discussion can, of course, touch upon aesthetic questions but it is not normally limited to them. They are not the only relevant questions, and other issues tend to come along. When it comes to our Corolla, we can consider whether it is good looking or dull, whether we like its color or how it continues the design tradition of Japanese cars. But very soon we normally end up talking about how it feels to drive it, how expensive it is, whether it is durable, whether it uses lots of gasoline, whether it is safe, whose it is, how old it is, etc. We might also ask why it seems to lack any real character when compared to more unusual cars, or whether we can know something about the owner simply through his or her car?

Which of these are aesthetic issues, strictly speaking? Perhaps the one about its looks? Why? Rather than trying to answer these questions right now, I would like to come back to them later. The point here is that no matter which issues are thought of as aesthetic, other issues tend to affect (our ideas about) them. We may think that a Corolla looks dull because there are so many of them, which, in turn, has to do with its price and with the technology one gets for that price. If we like the color, it may be because it is in fashion. However, fashion is a very complex social and economic phenomenon and it is not limited to aesthetics in any sense.

Furthermore, many find Corollas durable, relatively cheap and perhaps even dull, but all of these notions have to do with exactly the same materials and technology that are also related to the car's safety, driving feel and so on: there is nothing in the car that can be related to its aesthetics only - no material, function, form, technological solution or anything else. There is no part or aspect of the Corolla that could be separated with clear-cut borders and identified as one that concerns aesthetics and aesthetics only.

To make a comparison, it has been shown that aesthetic conceptions of human beings are normally intertwined with our overall conception of them. To put it simply: if we consider someone beautiful we tend to consider him or her morally good, intelligent and pleasant, as well, and vice versa. It has also been found that good-looking persons tend to get help very easily, say, when they are lost in a city, and they also get better grades at school. Moreover, they are noticed more often and doctors spend more time with them when they are in hospitals. There are exceptions of course, but this is the general, somewhat baffling tendency. Thus, our aesthetic opinions of people affect what we think of them and how we treat them in general, and our ideas about how 
intelligent or morally good someone is affects our idea of that how handsome, beautiful or ugly he or she is. ${ }^{3}$ Aesthetics is an important factor there, but it is the whole we are talking about, the whole person, and not some circumscribed part or aspect of him or her. A clear distinction or boundary between different aspects does not seem to exist.

The same tendency can be found in discourse on art, of course. In criticism it is perfectly normal to deal with such questions as who made the piece in question, what else has (s)he done, what material it is made of and was it an expensive project to produce it. All of these questions might easily affect our conception of, say, the beauty of a piece. They might also, for example, offer reasons for us to take a closer look at it in the first place. On the other hand, aesthetic issues are not always seen as very important in art. Joseph Kosuth is not alone in believing that the supposed borders of aesthetics do not have much to do with borders of art.

All in all, clear-cut boundaries between aesthetic issues and other issues seem to be hard to find. At least there seems to be heavy traffic across the borders, which seems to make them rather irrelevant.

Actually, of course, the fact that other issues tend to affect our ideas about the aesthetic ones does not mean that we should not postulate such borders in theory, analytically, if we want to.

The question is, however, do we need them? Should we want them? The problem they cause in the context of actual, concrete cases is that if we want to keep the discussion within certain boundaries and limit ourselves to aesthetic issues only, the whole discussion tends to become very narrow and lots of energy is expended on keeping an eye on the borders. But do we lose something if we talk about cars, human beings or paintings from a variety of perspectives? In fact, this is how we usually talk about these things. We are interested in their production history, materials, ecology, ethics and so on. I would claim that taking a wider perspective on anything makes understanding and experiencing it richer; focusing on aesthetics only is to focus on one side only and to leave the whole untouched. Thus, the problem with the borderline metaphor, in the worst case, is that it makes our perspective too narrow to be relevant. ${ }^{4}$

Thirdly, there are still other problems with the border metaphor. Namely, it is important to see that the borders are blurred even when we use simple terminology. Analytic postulating of borders also faces problems here: how can we describe and refer to aesthetic issues, and to them only, if we lack a distinctive vocabulary for aesthetic considerations? We do not always speak of
3 See Patzer 1985 and Kaiser 1999.

4 Similar ideas have been presented in many other contexts as well, of course. The notion resembles the ones presented by some Marxist and feminist critics whose target is the narrowly conceived modernist conception of art. 
beauty, ugliness, etc. but perhaps say only that a work of art or a car is good or fascinating. There is no certainty of the presence of aesthetics in such discourses in the first place, but it may be there as a part of a whole. However, the words used do not draw any clear limits here. Consider the much-used expression 'cool'; it does not respect any academically set borders for aesthetics. 'A cool car' can mean almost anything positive: well kept, expensive, uncommon, fast... Often such expressions have something to do with aesthetics but it may be hard to pinpoint what exactly.

Moreover, even the terms that are very often thought of as being at the core of aesthetics, like beauty or ugliness, schön, kaunis, bella or vacker, can be used with other meanings that are not aesthetic in any strict sense. In sports, one hears this often: one can "make a beautiful goal" and it means much more than just a good-looking goal in a narrow sense. It can be done, e.g., at an important moment considering the result of the game. On the other hand, a deed may be ugly, meaning that it is morally suspect, and so on. It is evident that this often used, non-distinctive terminology makes the idea of borderlines fairly peculiar.

Lastly, we often use no words at all. Talking, analyzing, reception with verbal language is only one option. Considering our Corolla again, we might ask where and when verbal aesthetics analysis takes place? It may take place in planning, but not necessarily even there, for nowadays planning is likely to be done by using visual computer software. There, verbal language comes up only occasionally. When actually driving our Corolla, verbal language is unnecessary. When driving, one does not have to talk. This does not necessarily mean that we are completely unaware of the aesthetic dimension of driving: we may try to turn a corner nicely and pay attention to the rhythm of the traffic. But then the aesthetic aspect is only one possible aspect of the overall situation and we do not often express this aspect verbally. Especially when we observe someone else driving, the presence of aesthetics is uncertain. By simply looking at someone we cannot be sure whether the driver is paying attention to the aesthetic dimensions of his or her action. We can, of course, project our own aesthetic ideas on him.

I tend to think that the very existence of aesthetics is heavily dependent on the verbal language we use, and when it is not used, it remains much more unclear whether it is noticed - in thinking or acting - in the first place. It becomes detectable as a thing we can identify as aesthetic only when we become conscious of it, often after we have done something, and this sort of consciousness is typically connected with verbal language. At such times, iden- 
tifying is naming. ${ }^{5}$ What a totally ineffable, wordless aesthetics would be - something that would not be at all, even in principle, connectable to verbal expressions that link the things in question to the tradition of aesthetics - is unclear.

But if we accept that aesthetically colored deeds and actions exist that need not be (but can be) verbally connected to the tradition of aesthetics at the moment when they take place, it seems hard to say where their aesthetic quality begins and ends. Driving a car or dancing as acts do not draw such borderlines (or many other borderlines either, for that matter). If one wants to have borders one necessarily needs to use language to draw them. For that purpose one typically makes use of theories - and we have just seen that it is not very easy to defend the idea of borders there either if one connects, as one should, the theory to practices of criticism and nonverbal deeds.

It seems that when we do or discuss something, aesthetics is not typically the central category we operate with. We talk about works of art and we want to understand them wholly. We meet people, we cook food, buy a car and so on, and all of these activities can be of aesthetic interest but our interest is not restricted to aesthetics. There are museums and galleries for art but not for 'aesthetic things'; to establish one would be an interesting enterprise!

I believe that it is difficult to find any boundaries for aesthetics that would separate aesthetic objects or language usages from non-aesthetic ones. Typically, aesthetic issues seem to be discussed as aspects or shades of the whole, sometimes they are not discussed clearly at all but only hinted at, and other issues affect them. They are not a separate category. All this is obvious in concrete cases of aesthetic practices, and I would claim that this should be taken into consideration in the theory of aesthetics as well. The borderline metaphor seems to suggest the contrary, and that is why I want to present another alternative.

Everything that I have said this far does not mean that aesthetic issues in our daily conversations and aesthetics as an academic discipline totally lack their own identity. Aesthetics is different from other disciplines. But the idea of an essential difference - one without which we cannot manage if we want to identify anything - does not need the idea of borders.

\section{Taste of aesthetics}

I would favor another metaphor, one that has been used in the history of aesthetics before but in a somewhat different way. Ac-
5 I do not wish to make any universal claims by this. I only believe that this is often the case. 
cording to it, aesthetics - or the aesthetic, das Ästhetische - is a tone, flavor or a shade in a totality, rather than a distinct area or totality on its own.

Following this path, assessing aesthetics - or the aesthetic - is closer to tasting food or wine: aesthetics is a part of the whole in the way saltiness or sweetness is a part of food or a drink. It cannot be pointed out that sweetness is exactly here, but not there. It is everywhere throughout whatever it is we are tasting. Such qualities as saltiness or sweetness have no borderlines between them and other tastes even if they have a distinctive flavor. In addition, aesthetics could be compared to having shades of color: it is more like a tint of yellow or blue in green than a separate patch of color. Likewise, aesthetics does differ from other nuances but is not separable from them.

Here, of course, I return to the old metaphor of taste, but only in certain respects. We need not adopt the ideas of standards of taste, the notion that something might be in 'good taste' or 'bad taste'. Consequently the problems of the relativity of taste and of the role of senses, knowledge, education, etc. in taste judgments must remain unresolved for now. ${ }^{6}$

The important thing to note is that taste, now, does not refer to a faculty possessed by certain, educated and sensitive persons. Anyone who is interested in wines learns to discern sweetness, age, the grape and so on, and this activity does not require a special sensitivity - the taste is found in an active interaction with the wine. Of course, some are better at this than others but there is nothing mystical about the activity. One does not need a special mouth or nose to taste different flavors.

Although someone might argue that wine-tasting is not for everyone, this is begging the questions. We all inevitably learn to discern numerous flavors, as we must eat and drink something, wine or something else, in order to keep on living. Likewise, most of us necessarily learn to taste the aesthetic in one way or another when we grow up in our particular cultures. It is hard not to learn to form opinions on beauty, ugliness etc. A taste, a hue, a flavor of an aesthetic sort is discerned in an interaction with things around us by anyone who is interested in it.

What makes tasting the aesthetic comparable to literal tasting done by the mouth and the nose is that in both we approach concrete wholes from many angles simultaneously and that there are no sharp borders between the angles. When we taste a portion of

6 These and related issues have been dealt with lately by Gracyk 1990, Gronow 1997 and Korsmeyer 1999. food we do discern differences between various flavors: salt, garlic, sage, basil and aceto balsamico, for example. In addition, we 
can taste whether the food is fresh and sometimes even its price category (caviar). These are different aspects of taste but they are all in the taste, so to speak, without clear limits or boundaries between them. Of course, there are attributes we cannot taste at all (origins of salt, weight of the portion, e.g.), and we have to get information about these in some other way. But the point is that if we want to taste whether there is basil or sage in the food we just have to taste it: taste as taste cannot be assessed in any other way. It is not the same thing to ask the cook to provide this taste to us.

If we stretch the metaphor a bit further, we could think that we can taste other things in a similar way, too. These might include politics or ethics, which seem to be as impossible to identify with the idea of borders as aesthetics is. They, too, seem to be aspects of practically everything, aspects that are always waiting to be noticed. Then, there might be issues we taste and others like weight or price we measure and describe by exact numbers and clear-cut borders. All of these can be considered in the context of our Corolla.

Moreover, we cannot literally taste everything in the world, but all of the things we can taste have some sort of taste, be it good or bad, sweet or salty. If we compare this to tasting aesthetics, ethics or politics, some sort of aesthetics, ethics and politics can be found wherever one is able and willing to judge it. Actually, it is hard to think of anything in the context of which the taste of aesthetics - or of the aesthetic - could not be focused on and found to be beautiful, ugly, cool, dull or something else. If one thinks in terms of borderlines, this ubiquitousness can easily be lost.

If so then the question is how do we discern the taste of the aesthetic from other tastes? Here, we need to refer to the history of aesthetics, both in the sense of concrete cases and aesthetic theory. We need to have some knowledge of the aesthetic discourse at large in order to taste whether something we encounter is related to it in some relevant way. If we talk about a car, we cannot measure whether it is cool and whether its coolness has something to do with beauty or something else that has been seen as having an aesthetic quality in our tradition before, but we have to assess it in a way that, to my mind, is comparable to tasting: we estimate it with our own senses and knowledge of things we have met before. Nobody can do this for us, for example by drawing $a$ priori clear-cut and universal borderlines for coolness. We cannot measure most tastes either but we can still discern them with our senses. We taste aesthetics and ethics with the help of the knowledge of their history and through examples we know, as we 
taste garlic and sage through our previous knowledge about these spices and food in general. ${ }^{7}$

\section{Why change?}

Why is it so important to reconsider the boundary metaphor in discussions of aesthetics? Because metaphors affect our thinking and attitudes. They are not just ways of speaking or harmless artistic figures, but something with the help of which we make sense of the world. So, we must ask what difference the taste metaphor might make in our thinking of aesthetics? The stress is on the word 'might', of course, because no metaphor guarantees anything about our thinking, but just supports some options.

The most important benefit of the taste metaphor is that when we use it in pondering aesthetic qualities, it is not easy to separate aesthetics from other issues. Tasting refers to assessing something in its totality: a food, wine or whatever. If we want to find out how something tastes, we do not typically search for one particular taste - whether it has garlic or beauty in it - but we are interested in the totality; the whole is good, interesting, boring etc. because it has garlic or beauty in it in this particular way in relation to its other aspects. If we want to be proficient in our assessments we need to know the tradition in which these things rest. We cannot have taste in any serious sense for anything we meet for the first time. Unlike garlic, however, aesthetics nowhere exists as a distinct species, but always occurs as mixed and along with other things. ${ }^{8}$

This makes aesthetics an important, intimate and inseparable part of a larger phenomenon. In principle, it cannot be put behind its own borders and then set aside when other, presumably more important issues are taken up. If we consider a whole, a totality, all of its aspects or dimensions should be taken into account and their relations to each other should be noticed. The taste metaphor helps us do this better than the borderline metaphor.

Another important aspect of the taste metaphor is that it does more to stress the corporeal, bodily nature of aesthetics than the border metaphor does. Tasting is often indulging in something, touching something with one's lips, palate, tongue and throat, or

7 I have elaborated the idea of identifying aesthetic issues with the help of history in more detail in Naukkarinen 1998.

8 One technical way of putting this is to talk about the so-called supervenience of aesthetics. smelling it. One takes this something inside of him and processes it with his whole body. At such time, one is in a very intimate relation with the thing being tasted. This tallies very well with the old notion that aesthetics is a 'science of sensitive knowledge' - aesthetic knowledge of the world cannot be had in any other 
way than through one's own senses, and that is true of tasting as well. Here, one moves away from visual metaphors, which have been very popular in many fields of knowledge, to a bodily metaphor. ${ }^{9}$ Borders, on the other hand, can be drawn on a map without being in close touch with a landscape, for example.

One must note, however, that no matter whether we choose the borderline or the taste metaphor, they both cause problems rather than resolve them. The taste approach only creates other problems, such as what makes the taste of the aesthetic differ from the taste of politics; how does metaphorical tasting differ from actual tasting; can aesthetics be assessed in any other way.

The advantage of the taste metaphor, in any case, is that it can remind us of this uncertainty and of these problems. It does not create the illusion that these problems can be solved for good by creating borders that exclude tough problems from the field. We are bound to taste things again and again. Our experiences will differ over time and we cannot be absolutely sure whether we even share the same taste with others. With this metaphor we indicate our acceptance of the situation that aesthetics will remain a problem that we will have to ponder. There is no final definition or a final experience of it, no matter whether we are looking at aesthetic issues on the level of concrete cases or at aesthetics as a theoretical discipline: we taste both and ponder whether we are experiencing aesthetics or ethics, whether we are perhaps experiencing something else this time. Drawing clear-cut borders gives us too simple a picture of what is an on-going endless discussion. ${ }^{10}$

\section{LITERATURE}

Entzenberg, Claes. 1998. Metaphor as a Mode of Interpretation. Uppsala University, Department of Aesthetics.

Gracyk, Theodor A. 1990. "Having Bad Taste", British Journal of Aesthetics, Vol. 30, No 2, April 1990, pp. 117-131.

Gronow, Jukka. 1997. The Sociology of Taste. Routledge.

Jay, Martin. 1994 (1993). Downcast Eyes. University of California Press.

Kaiser, Susan B. 1990. The Social Psychology of Clothing. Second edition. Macmillan Publishing Company.

Korsmeyer, Carolyn. 1999. Making Sense of Taste. Cornell University Press.

Lakoff, George and Mark Johnson. 1980. Metaphors We Live By. The University of Chicago Press.

Lakoff, George and Mark Johnson. 1999. Philosophy in the Flesh. Basic Books.

Naukkarinen, Ossi. 1998. Aesthetics of the Unavoidable. International Institute of Applied Aesthetics.

Patzer, Gordon. 1985. The Physical Attractiveness Phenomena. Plenum Press.
9 On the use of visual metaphors in the history of philosophy and sciences, see Jay 1994.

10 This article is a part of the research project Aesthetics, Mobility, and Change (Academy of Finland 201402) 